\title{
Study on the Prevalence of Melophagus Ovinus (Sheep Ked) In Berehet Woreda, Ethiopia
}

\author{
Gezahagn Nigate ${ }^{1}$ and Yeshibelay Girma ${ }^{2 *}$ \\ ${ }^{1}$ College of Agriculture, Department of Animal Health, Wollo University, Ethiopia \\ ${ }^{2}$ Ministry of Livestock and Fisheries, Addis Ababa, Ethiopia
}

Received: 21 August, 2018; Accepted: 11 September, 2018; Published: 03 October, 2018

*Corresponding author: Yeshibelay Girma, Ministry of Livestock and Fisheries, Addis Ababa, Ethiopia, Tel: +251912906079; E-mail: girmayeshibelay@ gmail.com

\begin{abstract}
A cross-sectional study on the prevalence of sheep ked was conducted in Berehet Woreda from December 2016 to June 2017 with the objectives of estimating the prevalence of sheep ked (Melophagus ovinus) and appraises potential risk factors of their attachment to sheep. Out of 384 sheep examined $7.55 \%$ were infested with Melophagus ovinus (M. ovinus). The overall prevalence of M. ovinus infestation was statistically significantly difference $(\mathrm{p}<0.05)$ among peasant association $(\chi 2=11.770 ; \mathrm{P}=0.0381)$, hair type $(\chi 2=4.2649$; $\mathrm{P}=0.0389)$; agro-climate regions $(\chi 2=6.855 ; \mathrm{P}=0.0325)$ and sheep ked prevalence statistically not significantly difference $(P>0.05)$ on sex $(\chi 2=0.3588 ; P=0.5492)$ and age group $(\chi 2=0.670 ; P=0.7155)$ categories of sheep. The sixth peasant association (Fura, Gorgo, Danceye, Geberoch, Wura, and Wane) infestation rate indicated as higher in Fura (13.85\%) followed by Gorgo (11.86\%) and lower in Wane $(5.41 \%)$ and Wura $(4.92 \%)$. In conclusion, small ruminants (sheep) are reared; the importance of ectoparasites (sheep ked) should be considered as it result a great economic losses, the impact of the disease caused by external parasites is severely limiting the performance of the tanning industries, which in turn affect the country's foreign currency warranted an urgent control intervention. Therefore: effective extension system and programs that could raise public awareness on how to care and handle their animals. Control programs should be designed and implemented with the participation of all stakeholders (farmers, tanners, government, privet sectors and veterinarians). Further studies should be conducted on the epidemiology of ectoparasites and skin disease in different agroecology parts of the country.
\end{abstract}

Keywords: Ked; Prevalence; Sheep; Berehet Woreda

\section{Introduction}

In Ethiopia virtually 25.5 million sheep are reared in varied agro-ecologies and production systems for multiple purposes such as meat production, income generation, and as a source of skin (CSA, 2013; Mengesha and Tsega, 2012); contributing significantly to small scale farmers' livelihoods (ESGPIP, 2009) $[6,8,16]$. Contribution from sheep production to Ethiopian economy is adversely affected by several constraints. The subclinical parasitism due to endo and ecto parasitism form the main factors (Berhanu, et al., 2011) [3]. Ectoparasites are however being more important in the changing scenario as they have a range of direct and indirect consequences on their hosts
(James-Rugu and Jidayi, 2004) [11].

Sheep keds are wingless dipteran flies of the family Hippoboscidae that feed on host blood via their piercing mouthparts. The relationship with the host is intimate and obligatory, with the whole reproductive cycle taking place in the fleece of the host; the female ked produces a single full-grown larva periodically, which becomes firmly attached to the wool and forms a puparium in situ (Small, 2005) [23]. Keds of small ruminant feeds on the blood of their hosts thus cause blood loss leading to anaemia (Radostatits, et al., 2007) [19]. They cause irritation to the skin and stimulate scratching, rubbing, and licking leading to restlessness, damage to the fleece and skin and reduction in carcass weight (Kebebew, 2015) [13]. Furthermore, Ked and lice of sheep cause downgrading and rejection of sheep skins (Phillips, 2005) thus, adversely affect productivity and reproductive efficiency [18]. Ectoparasites are also vector for various diseases (Petney et al., 2007) [17]. Furthermore, ectoparasites have major impact on welfare of their hosts (Colebrook and Wall, 2004) [5]. In general, external parasitism adversely affect economic production of sheep resulting in poor sheep products particularly skins thus causes huge losses in terms of income to producers, the skin processing and export industries and the country at large (ESGPIP, 2010; Kumsa et al., 2012) $[9,14]$. Transfer from sheep to sheep is by direct contact, typically from ewe to lamb. Despite the fact that heavy infestation with ked causes irritation and damage to the fleece and hide, potentially leading to economic losses (Small, 2005) [23].

Ethiopia used to get the second largest foreign currency earnings from the export of skins and hides which has been deteriorating due to the decrease in skin quality owing to the increase in external parasite infestations (ESGPIP, 2010) [9]. Annually, sheep skin contributes about $30 \%$ of skins and hides production based on off take rate (Kebebew, 2015) [13]. However, studies in the country indicated that ectoparasites are becoming growing threat for small ruminant production and export of skin in Ethiopia and it has been reported that about 35\% of sheep skin rejections in the country are due to external parasitism (Kumsa, et al., 2012; Kassa, 2006) [12,14]. Both lice and ked are considered as a cause of 'ekek' in Ethiopian sheep skins thus, play 
a major role in the continuous declining in quality of skin of small ruminants including sheep (Desta, 2004) [7].

In Ethiopia, Different researchers reported from some parts of the country indicated that ectoparasitism of sheep is still alarming condition in Ethiopia (Berhanu, et al., 2011; Kebebew, 2015; Kumsa, et al., 2012; Chanie, et al., 2010; Sertse and Wossene, 2007) $[3,4,13,14,20]$. There is a gap for many potential sites of the country and information is not available to review country wide prevalence and economic significance. In Berehet woreda there is no any information or data about the prevalence of sheep ked. Therefore, the objectives of this study were to identify and estimate the prevalence of sheep ked infestations in their hosts' natural environment and to assess the association between the parasitic infestation and the risk factors of their attachment to sheep in the study area.

\section{Materials and Methods}

\section{Study Area}

The study was conducted in Berehet woreda, North Shewa zonal administrative in the Amhara Regional states of Ethiopia. This area has sub tropical weather "Weyna dega", high land temperature type "Dega" and low land temperature type "Kola" accounting $17 \%, 3 \%$ and $80 \%$ of the climate respectively. The woreda is located at $220 \mathrm{~km}$ east of Addis Ababa the capital city of Ethiopia. The mean annual temperatures and rainfall rages between 18 to $33{ }^{\circ} \mathrm{C}$ and 750 to $850 \mathrm{~mm}$ respectively. The altitude of the area ranges from 1000 to 3200 meter above sea level. Mixed farming is the main economic activities of the woreda $80 \%$ common agricultural crops like beans, peas, wheat, barley, sorghum, corn, and teff are cultivated in the area. The livestock population of the woreda is estimated at 30,859 Cattle, 36,190 Goat, 20,419 Sheep, 8,334 Equine, 2,760 Camel and 42,759 Poultry (Berehet woreda Livestock office data, 2016) [2].

\section{Study Animals}

A total of 384 sheep from the woreda were subjected to in this study to determine the overall prevalence rates on the study area. All examined animals were local breeds of different age groups, sex and hair types. The animals were grouped into three age categories as young ( $<1$ year), adult (1-3 years) and old ( $>3$ years) based on dentition (ESGPIP, 2009) [8].

\section{Study Design}

A cross sectional study method was conducted by selecting animals randomly to determine the prevalence of sheep keds in the woreda and also detects the common attachment sites of the parasites on the animal's body.

\section{Sampling Method and Sample Sizes}

Simple random sampling methods were applied to taken the samples and the sample frame was peasant associations (PA) found within Berehet woreda. From the selected 6th PA (i.e Fura, Gorego, Danceye, Gebroch, Wura and Wane) the sample size was calculated by using $50 \%$ expected prevalence to get the sample size, because there was no previous prevalence studies in the woreda. Using Thrusfield (2007) formula; accordingly, the minimum sample size needed was 384 .

$$
n=\frac{(1.96)^{2} P_{\exp }\left(1-P_{\text {exp }}\right)}{d^{2}}
$$

Where: $\mathrm{n}=$ required sample size; $\mathrm{P}_{\exp }=$ expected prevalence; $\mathrm{d} 2=$ desired absolute precision of 95 confidence interval.

\section{Ectoparasites Collection and Identification}

Following proper restraining of the sheep clinical examination was performed as described by Kumsa, et al. (2012) [14]. The skin was palpated across all parts of the animal for the presence of parasites, and gross lesions suggestive of a clinical form of sheep ked infestations and animals found infested were considered as positive (Kumsa, et al. 2012) [14]. Visual inspection of the skin and wool were conducted to detect parasites. The parasite was removed carefully and gently by hand and forceps to avoid any damage on the body. The collected ked from their attachment site inserted into universal bottles containing $70 \%$ ethyl alcohol labeled with animals.

particularities and transported to Parasitology laboratory, further identification of the parasites were conducted under stereomicroscope according to the identification keys of Urquhart, et al. (1996) and Wall, et al. (2001) [25,26].

\section{Data Analysis}

Data collected from laboratory result was stored on Microsoft excel spread sheet program, and analysis was done by using SPSS version 20 software program. Descriptive statistics were used to describe and process the data. Categorical variables (sex, age, PA, body hair type and agro-ecology conditions (kola, dega and weyna dega) were expressed in percent. Prevalence was defined as the proportion of the animals (sheep) positive for sheep keds to the total of animals examined, which was expressed in percent. The association between each risk factors and the outcome variable were analyzed by using Chi square $(\chi 2)$ test. For all tests, p-value less than 0.05 were considered to be significant.

\section{Results}

Out of 384 sheep examined 29 (7.55\%) were infested by sheep ked (M. ovinus). The prevalence of sheep ked in the six selected peasant association (PA) were 13.85\%, 11.86\%, 9.52\%, $4.92 \%, 5.41 \%$ and $5.41 \%$ in Fura, Gorgo, Dancye, Wura and Wane respectively. The prevalence of sheep ked between the study sites showed statistically significant difference (Table 1).

Analysis of the prevalence rate on age basis showed no significant difference $(\mathrm{P}>0.05)$ 10\%, 8.51\% and 6.8\% were young, adult and old respectively (Table 2).

Infestation rate of sheep ked between male and female animals were compared. Statistically analysis showed no significant difference $(\mathrm{P}>0.05)$ (Table 3$)$.

The prevalence of sheep keds on hairy and woolly sheep was $13.15 \%$ and $6.17 \%$ respectively. Statistical significant difference showed $(\mathrm{p}<0.05)$ (Table 4). 
Table 1: Prevalence of sheep ked in Peasant Associations (PA)

\begin{tabular}{|c|c|c|c|}
\hline PA & No. of animal Sampled & No. of animal positive & Infection rate $(\%)$ \\
\hline Fura & 65 & 9 & 13.85 \\
\hline Gorgo & 59 & 7 & 11.86 \\
\hline Dancye & 63 & 6 & 9.52 \\
\hline Gebroch & 62 & - & - \\
\hline Wura & 61 & 3 & 4.92 \\
\hline Wane & 74 & 4 & 5.41 \\
\hline Total & 384 & 29 & 7.55 \\
\hline
\end{tabular}

Table 2: prevalence of sheep ked in age bases

\begin{tabular}{|c|c|c|c|}
\hline Age & No. of animal Sampled & No. of animal Positive & Prevalence (\%) \\
\hline Young & 40 & 4 & 10 \\
\hline Adult & 94 & 8 & 8.51 \\
\hline Old & 250 & 17 & 6.8 \\
\hline Total & 384 & 29 & 7.55 \\
\hline
\end{tabular}

Table 3: prevalence of sheep ked in sex bases

\begin{tabular}{|c|c|c|}
\hline Sex & No. of animal Sampled & No. animals Positive \\
\hline Female & 218 & 18 \\
\hline Male & 166 & 11 \\
\hline Total & 384 & 29 \\
\hline$\chi 2=0.3588, P$ - value $=0.5492$, the result is not significant at $P<0.05$. \\
\hline
\end{tabular}

Table 4: prevalence of sheep ked infestation on hair type

\begin{tabular}{|c|c|c|c|}
\hline Hair type & No. of animal Sampled & No. animal Positive \\
\hline Woolly & 76 & 10 & 19 \\
\hline Hairy & 308 & $\mathbf{2 0}$ & $\mathbf{2 9}$ \\
\hline Total & $\mathbf{3 8 4}$ & $\mathbf{7 . 5 5}$ \\
\hline$\chi 2=4.2649, P$ - value $=0.0389$, the result is significant at $P<0.05$. & \\
\hline
\end{tabular}

Table 5: prevalence of sheep ked in different agro-climatic regions

\begin{tabular}{|c|c|c|}
\hline Agro-climatic zones & No. animal sampled & No. animal positive \\
\hline Kola & 59 & - \\
\hline W/dega & 129 & 9 \\
\hline Dega & 196 & 20 \\
\hline$\chi 2=6.855$, the $P$-value is 0.0325 ; the result is significant at $P<0.05$. & 10.2 \\
\hline
\end{tabular}


The prevalence of sheep keds in Kola, Weyna dega (W/ dega) and Dega agro-climatic regions was 0\%, 6.97\%, and $10.2 \%$ respectively. The prevalence of M.ovinus was statisticaly significant difference showed on agro-climatic regions (Table 5).

Of these $M$. ovinus infestation the common site on sheep body were 13/29 (44.83\%) shoulder, 7/29 (24.14\%) neck, $5 / 29(17.24 \%)$ rump and $2 / 29(6.9 \%)$ lateral sides and belly as indicated in Figure (1)

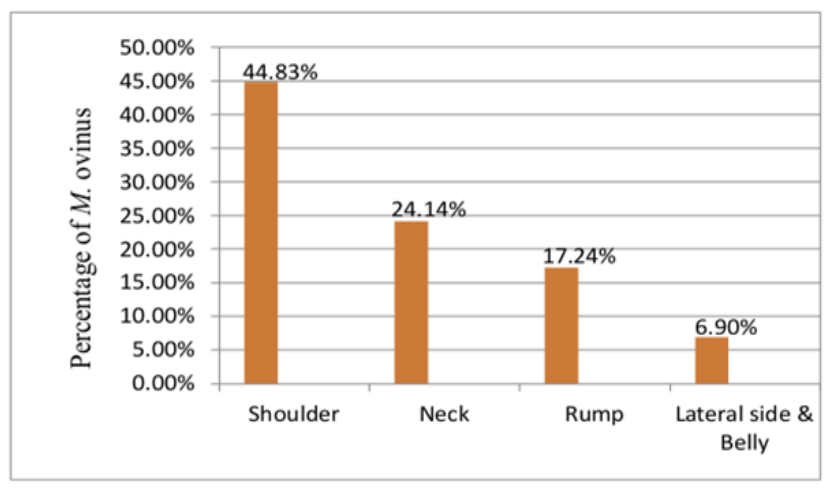

Figure 1: The common sites of $M$. ovinus on sheep bodies

\section{Discussions}

The results of the present study revealed that the overall prevalence of M. ovinus infestation was $7.55 \%$ in sheep reared in the extensive production system in the study areas. According to Shiferaw (2018) report the prevalence of sheep ked in different parts of Ethiopia were $6.70 \%, 3 \%, 20.10 \%, 32.57 \%, 11.67 \%$, $16.40 \%$ and $14.2 \%$ in Tigray, Bahir-Dar, Gondar, Kombolcha, Tigray region, Central oromia and Southern Ethiopia respectively [22]. The present finding was

relatively agreed with this reports conducted in Tigray were $6.70 \%$. In the other parts of Ethiopia relatively higher prevalence reported by Shiferaw (2018) in Kombolcha, Gondar, Central oromia, Southern Ethiopia and Tigray region were 32.57\%, $20.10 \%, 16.40 \%, 14.20 \%$ and $11.67 \%$ respectively [22].

According to the previous report conducted by Bekele, et al. (2011), Seyoum, et al. (2015), Desta, et al.(2004), Kumsa, et al.(2012), Eshetu, et al.(2017) higher prevalence of ectoparasites in sheep and goat in different parts of Ethiopia where prevalence as high as $81.5 \%$ and $71.63 \%[1,7,10,14,21]$. The prevalence of M. ovinus in the present findings was $7.55 \%$ this is relatively lower compared to the reports of Desta, et al. (2004), Chanie, et al.(2010) Kumsa, et al.(2012), Eshetu, et al.(2017) were 36.5\%, $32.99 \%, 31.7 \%$ and $33.57 \%$ reported in highland areas of Oromia and Amhara regions of Ethiopia respectively [4,7,10,14]. This might be due to different climatic condition, poor husbandry practices, low attention given to the ectoparasites and their effects on animals' health, insufficient awareness of the animals' owners on ectoparasites and inadequate flock health program in the area (Chanie et al., 2010). In agreement, the current findings $7.55 \%$ was similar with the findings of some other studies, where similar overall prevalence of M. ovinus were 9.2\% (Seyoum, et al. 2015), 8.07\% (Bekele, et al, 2011) and 6.70\% (Shiferaw, 2018) in and around Sekela district of Amhara region and in Wolmera district of Oromia region and in Tigray region respectively [1,21,22]. In contrast, the current study $7.55 \%$ was higher compared to other study, where lower overall prevalence of M. ovinus 3\% Shiferaw (2018) were reported from Bahir Dar [22].

Statistical analysis revealed that sex of animals not significantly difference on the prevalence of M. ovinus infestation in sheep $(\mathrm{P}>0.05)$. This might be suggested that two sexes are equivalently susceptible for ked infestations. Similarly, there was no statistical significance difference in the prevalence of $M$. ovinus in the agro-climatic regions of the study area. According to Radostatits et al. (2007) and wall and Shearer (2001) in the hot and humid tropics the parasite is restricted to cooler highlands and infestations may be lowest when sheep are moved to hot dry areas $[19,26]$. Temperature may play an important role in the dynamics of the ked (Wall and Shearer, 2001). The present study indicated that $M$. ovinus was prevalent in sheep accounting for $7.55 \%$ prevalence. Statistical significant difference showed $(p<0.05)$ in the body cover hairs, higher prevalence of $M$. ovinus infestation was observed in woolly sheep (13.15\%) compared to hairy sheep (6.17\%). According to Wall and Shearer (2001) description woolly sheep are more susceptible to ked infestations and Urquhart et al. (1996) also stated that shearing might be removed a high proportions (80-90\%) of ked populations from sheep.

Furthermore, statistically not significantly differences $(\mathrm{P}<$ 0.05 ) in the prevalence of the M. ovinus between ages group of sheep was also observed. The result of this study indicated that young sheep were more vulnerable to $M$. ovinus infestation than old animals. The observation was higher prevalence of M. ovinus in young than in adult and old sheep is described by the movement of ked from ewe to lamb as an important source of infestation (Kumsa et al., 2012) [14]. It has also been documented that, young animals are generally more susceptible to ectoparasites because of their immature immunity, a higher ratio of accessible surface to the body volume and poor grooming behavior (Lehmat, 1993) [15].

\section{Conclusions and Recommendations}

In Ethiopia, Ectoparasites of the animals are currently a disease of considerable importance in domestic animals production sector as a major cause of down grading and rejection of skin and hide. M. ovinus is one of ectoparasites of sheep and it is impacts of the problem both on the health of the animals and their performance. This study was conducted that the prevalence of M. ovinus and its associated factors in the study area. The result of this study indicated that sheep ked is prevalent in the area. M. ovinus infestations in the study area are not an outcome of a single determinant, but also consequent to the effects of multiple factors such as poor management, poor plan of nutrition and hygienic conditions. Therefore improving husbandry practices and veterinary services may reduce the level of Ectoparasites. Moreover, the impact of the disease caused 
external parasites is severely limiting the performance of the tanning industries, which in turn affect the country's foreign currency warranted an urgent control intervention. Based on the above conclusion remarks, the following recommendations are forwarded:

$\sqrt{ }$ Effective extension system and programs that could raise public awareness on the effect of skin disease on production, productivity, skin/ hide quality as well as how to care and handle their animals.

$\sqrt{ }$ Control programs should be designed and implemented with the participation of all stakeholders (farmers, tanners, government, privet sectors and veterinarians).

$\sqrt{ }$ Further studies should be conducted on the epidemiology of Ectoparasites and skin disease in different agro-ecology parts of the country.

\section{Acknowledgments}

First we would like to sincerely thank Berehet woreda Agricultural office and Wollo University staff members for their unlimited supports and advices. Finally we would like to thank all proponents to our works from beginning to end for their encouragement and faith to our successfulness.

\section{Conflicts of Interest}

We declare that there is no any conflict of interest.

\section{References}

1. Bekele J, Tariku M, Abebe R. External parasite infestation in small ruminants in Wolmera district of Oromiya region, central Ethiopia. J Anim Vet. Adv. 2011;4:518-523. DOI: 10.3923/javaa.2011.518.523

2. Berehet woreda Livestock Office Annual Report (2016).

3. Berhanu W, Negussie H, Alemu S, Mazengia H. Assessment on major factors that cause skin rejection at Modjo export tannery, Ethiopia Trop Anim Health Prod. 2011;43(5):989-993. DOI: 10.1007/s11250011-9796-2

4. Chanie M, Negash T, Sirak A. Ectoparasites are the major causes of various types of skin lesions in small ruminants in Ethiopia. J Trop Anim Health Prod. 2010;42(6):1103-1109. DOI: 10.1007/s11250010-9531-4

5. Colebrook E, Wall R. Ectoparasites of livestock in Europe and the Mediterranean region. Vet Parasitol. 2004;120(4):251-274. DOI: 10.1016/j.vetpar.2004.01.012

6. CSA. Livestock and livestock characteristics survey 2012-13 (private peasant holdings) Statistical bulletin no. 570, Addis Ababa, Ethiopia. 2013

7. Desta TS. Investigation on ectoparasites of small ruminants in selected sites of Amhara regional state and their impact on the tanning industry. MSc Thesis submitted to Faculty of Veterinary Medicine, Addis Ababa University, Ethiopia. 2004.

8. ESGPIP (Ethiopian Sheep and Goats Productivity Improvement Program). Sheep breeds of Ethiopia: guide for identification and utilization. Technical Bulletin no.28. 2009.
9. ESGPIP (Ethiopian Sheep and Goats Productivity Improvement Program). Control of external parasites of sheep and goats. Technical Bulletin No. 41. 2010.

10. Eshetu A, Ayele T, Mengistu S, Belina D. Prevalence of Melophagus ovinus and Bovicola ovis infestation in sheep in Wogera District, North Gondar Zone, Ethiopia. J Vet Sci Technol. 2017;8(3):1-5. DOI : 10.4262/2157-7579.1000440

11. James-Rugu NN, Jidayi S. A survey of the ectoparasities of some livestock from some areas of Borno and Yobe States. Nigerian Vet J. 2004;25:48-55.

12. Kassa B. Cockle, manage and pox: major threats to the leather industry in Ethiopia in Ethiopian Leather Industry: Prevalence towards Value Addition. Proceedings of the National Workshop, December 14-15, 2006, Addis Abeba, Ethiopia. 2006;71-92.

13. Kebebew G. Experimental study on sheep infested with B. ovis and M. ovinus of pathological changes, processed skin defect and effect of treatment in improving skin quality. MSc Thesis submitted to College of Veterinary Medicine and Agriculture, Addis Ababa University. 2015.

14. Kumsa B, Beyecha K, Geloye M. Ectoparasites of sheep in three agroecological zones in central Oromia, Ethiopia. Onderstepoort. J Vet Res.2012;79(1):E1-7. DOI: 10.4102/ojvr.v79i1.442.

15. Lehman T. Ectoparasites: Direct Impact on Host Fitness. Parasitol Today. 1993;9(1):8-13.

16. Mengesha M, Tsega W. Indigenous sheep production in Ethiopia: A review Iranian. J Appl Anim Sci. 2012;2(4):311-318.

17. Petney TN, Kolonin GV, Robbins RG. Southeast Asian ticks (Acari: Ixodida): a historical perspective. Parasitol Res. 2007;101: 201-205. DOI: $10.1007 / \mathrm{s} 00436-007-0687-4$

18. Phillips CJC. The Effects of External Parasites and their Control on the Welfare of Livestock. Center for Animal Welfare and Ethics School of Veterinary Science, University of Queensland. 2005:63.

19. Radostatits OM, Gray K, Hinchcliff H. Constable P. A Textbook of the Disease of Cattle, Horses, Sheep, Pigs and Goats. 10th ed. WB Saunders, Edinburgh, UK. 2007.

20. Sertse T, Wossene A. A study on ectoparasites of sheep and goats in eastern part of Amhara region, northeast Ethiopia. Small Ruminant Res. 2007;69(1-3):62-67.

21. Seyoum Z, Tadesse T, Addisu A. Ectoparasites Prevalence in Small Ruminants in and around Sekela, Amhara Regional State, Northwest Ethiopia. J Vet Med. 2015;4:1-7.

22. Shiferaw S. An Overview of Ectoparasites on Domestic Animals in Ethiopia. J Veter Sci Med. 2018;6(1):1-5.

23. Small RW. A review of Melophagus ovinus, the sheep ked. Veterinary Parasitology. 2005;130(1-2):141-155.

24. Thrusfield M. Veterinary Epidemiology. 3rd edn. Blackwell Science Ltd., London, UK. 2007:228-246.

25. Urquhart GM, Armour J, Duncan AM, Jennings FW. Veterinary Parasitology. 4th ed. Blackwell Science, Glasgow, Scotland. 1996.

26. Wall R, Shearer D. Veterinary External Parasites: Biology, Pathology and Control. 2nd ed. Blackwell Science LTD, New Jersey, USA. 2001. 